\title{
Epidemiology of Pars Plana Vitrectomy in the Elderly: A Retrospective 10-Year Survey of 592 Cases
}

\author{
Sivan Elyashiv $\mathbb{D}^{1,2}$ \\ Miri Fogel Levin ${ }^{1,2}$ \\ Ofira Zloto ${ }^{1,2}$ \\ Eli Neimark (1D ${ }^{3}$ \\ Riham Najjar ${ }^{4}$ \\ Joseph Moisseiev ${ }^{1,2}$ \\ Orit Vidne-Hay ${ }^{1,2}$
}

'Goldschleger Eye Institute, Sheba Medical Center, Tel Hashomer, Israel; ${ }^{2}$ Sackler School of Medicine, Tel Aviv University, Tel Aviv, Israel; ${ }^{3}$ Ben Gurion University of the Negev, Beer Sheba, Israel; ${ }^{4}$ The Technion - Israel Institute of Technology, Ruth and Bruce Rappaport Faculty of Medicine, Haifa, Israel
Correspondence: Sivan Elyashiv

Goldschleger Eye Institute, Sheba Medical

Center, Tel-Hashomer, Israel

Tel +97235302874

Fax +97235302822

Email sivan.elyashiv@sheba.gov.il
Purpose: To report the epidemiology of the surgical indications of pars plana vitrectomy in patients aged 75 years or older.

Patients and Methods: The medical records of patients who underwent vitrectomy surgery in a single center between 2008 and 2018 were evaluated retrospectively for demographics, medical background, and surgical indications. Data on patients aged $75-85$ were compared to those of patients older than 85 years and those recorded between 2008-2013 and 2014-2018. Results: A total of 592 patients were included, of whom $55 \%$ were males. The mean \pm standard deviation age of the cohort at presentation was $80.4 \pm 4.60$ years, and the mean visual acuity was $1.3 \pm 0.93 \operatorname{logMAR}$. The main indications for surgery were retinal detachment $(n=117$, 19.7\%), epiretinal-membrane/vitreomacular traction $(n=140,23.6 \%)$, dropped intraocular lens/ retained lens $(n=89,15 \%)$, macular hole $(n=64,11 \%)$, submacular hemorrhage $(n=40,6.7 \%)$, diagnostic vitrectomy $(n=37,6.2 \%)$, non-diabetic vitreous hemorrhage $(n=30,5.1 \%)$, and diabetic vitreous hemorrhage and other diabetic complications $(n=33,5.6 \%)$. Patients aged 85 years and older had higher rates of urgent surgeries $(65 \%)$, such as for submacular hemorrhage and trauma ( $p=0.0000039$ and $p=0.001$, respectively), and lower rates of nonurgent surgeries, such as for epiretinal membrane and macular hole $(p=0.000032$ and $p=0.02$, respectively), compared to patients aged 75-84 years. Additionally, the surgical rate for submacular hemorrhage decreased during 2008-2014 compared to 2014-2018 ( $p=0.000014)$.

Conclusion: Understanding the unique distribution of indications for vitrectomy among elderly patients is essential for appropriate management and treatment. Urgent cases represent $65 \%$ of the surgeries performed in the older population.

Keywords: aged, epidemiology, pars plana vitrectomy

\section{Introduction}

By 2050, the number of persons aged 80 years or older is estimated to triple. ${ }^{1}$ This demographic change will lead to a considerable rise in the number of people afflicted with major eye conditions that cause vision impairment, ${ }^{2}$ since those pathologies increase in prevalence with age. These two developments will mandate adjustments in ophthalmic care practices.

Surgery to preserve or improve vision has been shown to reduce the risk of falls, increase activity, and enhance the sense of security and well-being in the elderly. ${ }^{3}$ Several studies have recognized the interrelation between visual acuity (VA), cognitive functions, and dementia, ${ }^{4,5}$ some implying that early intervention may reduce the severity of dementia. ${ }^{6}$ However, age-related systemic and ocular 
comorbidities may potentially complicate the perioperative period, restrict postoperative care, ${ }^{7,8}$ and limit visual outcomes in older population undergoing ocular surgery. ${ }^{9-11}$ While some studies on anterior segment ocular surgery outcomes in the elderly observed a clear benefit for surgery in these patients despite lower VA outcomes when compared to the same procedure performed in younger patients, ${ }^{12,13}$ comorbidities and handicaps in the elderly may dissuade the surgeon from performing elective retinal procedures, thereby delaying surgery and potentially hampering outcomes.

Research is scarce on pars plana vitrectomy (PPV) in the elderly, and the existing reports mostly describe small cohorts with relatively short follow-up periods. ${ }^{14}$ Anteby et al reported improved VA in more than one-half of the patients in a cohort of 82 elderly patients who underwent PPV for several indications. ${ }^{15}$ Moisseiev et al reported a cohort of 29 eyes of patients aged 75 years and older who underwent surgery for epiretinal membrane (ERM). The mean improvement in VA was $0.23 \log$ MAR, and the complication rate was comparable to those of previous studies on cohorts of all ages. ${ }^{16}$

This retrospective study was undertaken to investigate the indications of PPV surgery in patients aged 75 years and older in anticipation of the upcoming changes in the character of the patient population seeking retina care.

\section{Patients and Methods}

The computerized medical records of all patients aged 75 years and older that underwent primary PPV (both elective and emergent) at the Goldschleger Eye Institute of Sheba Medical Center between January 1, 2008 to December 31, 2018 were retrieved by query from the departmental database. The data were retrospectively evaluated for demographics, medical and ocular background, as well as surgical indication. The Sheba Medical Center Institutional Review Board approved the study. Patient consent was waived for this retrospective investigation that used de-identified data, thereby assuring patient confidentiality. The study complied with the ethical standards of the 1964 Helsinki Declaration and its later amendments or comparable ethical standards.

Patients operated between 2008-2013 were compared to those operated between 2014-2018, and between individuals aged $75-84$ years and those aged $\geq 85$ years. The urgency of the procedure was assessed based on the acceptable interval between diagnosis and surgery as follows:
- Urgency was defined as surgery performed within 7 days of diagnosis. Urgent cases included: retinal detachment (RD), dropped IOL, dropped lens, submacular hemorrhage (SMH), endophthalmitis, diagnostic vitrectomy, trauma, and malignant glaucoma.

- Mid-urgency was defined as surgery performed 1-4 weeks from diagnosis. Mid-urgent cases included: macular hole $(\mathrm{MH})$, non-diabetic vitreous hemorrhage (retinal detachment and retinal tears were ruled out based on ultrasound examination findings), and diabetic complications (other than vitreous hemorrhage [VH]).

- Low-urgency was defined as surgery performed more than 4 weeks after diagnosis. Low-urgency cases included ERM, vitreomacular traction (VMT), diabetic $\mathrm{VH}$, asteroid hyalosis, and "other" diagnoses that were evaluated case-by-case.

\section{Statistical Analysis}

The statistical analysis aimed to explore the association between the patients' demographics, medical parameters, VA (converted to $\log$ MAR VA), and the time from diagnosis to surgery. A logarithmic transformation was applied since both of those parameters were asymmetrically distributed. The $t$-test and analysis of variance were used to compare groups of patients with regard to the transformed $\operatorname{logMAR}$ VA and interval between diagnosis and surgery as applicable. The chi-square test was performed to examine the association between categorical variables (eg, age group and diagnosis). A linear regression model was applied to the data to study the simultaneous association of sex, age group, various systemic diseases, and ocular comorbidities with $\log$ MAR VA. A repeated regression was performed, including the number of diagnoses per patient instead of specific diagnoses. The model selection methods stepwise selection and maximal adjusted R-square were applied.

\section{Results}

In total, 592 cases were included in this epidemiological analysis, of which $55 \%(\mathrm{n}=328)$ patients were males. The mean \pm standard deviation age of the entire cohort at presentation was $80.4 \pm 4.60$ years. The mean VA at presentation was $1.3 \pm 0.93 \operatorname{logMAR}$, and the mean IOP was 15.87 $\pm 6.80 \mathrm{mmHg}$ with a median of no (zero) anti-glaucoma medications. The indications for surgery are shown in Table 1. 
Table I Distribution of Indications for Pars-Plana Vitrectomy by Age Group

\begin{tabular}{|c|c|c|c|c|}
\hline Total & Total & $\begin{array}{c}\text { 75-84 Years } \\
\text { Number of Cases (\%) }\end{array}$ & $\begin{array}{l}85 \text { Years and Older } \\
\text { Number of Cases (\%) }\end{array}$ & $P$ value \\
\hline Retinal detachment & 117 & $|0|(2 I)$ & $16(14)$ & NS \\
\hline ERM & 111 & $106(22)$ & $5(5)$ & 0.000032 \\
\hline VMT & 29 & $24(5)$ & $5(5)$ & NS \\
\hline $\mathrm{MH}$ & 64 & $59(12)$ & $5(5)$ & 0.02 \\
\hline SMH & 40 & $23(5)$ & $17(16)$ & 0.0000039 \\
\hline Dropped IOL/retained lens fragments & 89 & $70(14)$ & $19(18)$ & NS \\
\hline NDVH & 30 & $17(4)$ & $13(12)$ & 0.00026 \\
\hline Diabetic vitreous hemorrhage and complications & 33 & $27(6)$ & $6(5)$ & NS \\
\hline Diagnostic vitrectomy & 13 & $10(2)$ & $3(3)$ & NS \\
\hline Endophthalmitis & 24 & $17(4)$ & 7 (7) & NS \\
\hline Trauma & 8 & $3(1)$ & $5(5)$ & 0.001 \\
\hline Other & 20 & $16(3)$ & $4(4)$ & NS \\
\hline Malignant glaucoma & 14 & II (2) & $3(3)$ & NS \\
\hline Total & 592 & $484(82)$ & $108(18)$ & \\
\hline Male & $328(55)$ & $268(55.3)$ & $55(50.9)$ & NS \\
\hline
\end{tabular}

Abbreviations: ERM, epiretinal membrane; VMT, vitreomacular traction; MH, macular hole; SMH, sub-macular hemorrhage; NDVH, nondiabetic vitreous hemorrhage.

Cardiovascular diseases were reported in $79.22 \%$ of the study patients $(\mathrm{n}=469)$, neoplastic diseases in $13 \%(\mathrm{n}=77)$, inflammatory diseases in $2.19 \%(\mathrm{n}=13)$, lung and respiratory diseases in $2.36 \%(\mathrm{n}=14)$, and other diseases in $24.49 \%(n=145)$. No statistical correlation was found between any systemic disease or the number of systemic diseases with the best-corrected visual acuity (BCVA) at presentation, nor was there any correlation between the number of systemic diseases and the interval between diagnosis to surgery. No systemic diseases were reported in $5 \%$ of the patients $(n=30)$.

Altogether, $2.87 \%$ of the study patients $(\mathrm{n}=17)$ had no ocular history, and $52.19 \%(\mathrm{n}=309)$ had at least one pseudophakic eye. Glaucoma was documented in $18.91 \%$ of the patients $(\mathrm{n}=112)$, age-related macular degeneration (AMD) in $8.27 \%(n=49)$, diabetic retinopathy in $7.09 \%$ $(n=42)$, and other ocular comorbidities (such as corneal opacities, vascular occlusions, and trauma) in $13.34 \%$ $(\mathrm{n}=78)$. Seventy-one patients $(11.99 \%)$ had received intravitreal injections for neovascular AMD or diabetic macular edema.

\section{Comparison Between the 75- to 84-Year and the $\geq 85$-Year Age Groups}

The distribution of indications for PPV by age group is shown in Table 1. The rate of surgeries for ERM and MH was significantly higher in the 75-85 year age group, whereas the rates for surgeries due to trauma, SMH, and non-diabetic VH were significantly higher in the older age group. The distribution of the urgency level of PPV by age group is shown in Table 2, revealing a significant difference between the two age groups. Low-urgency surgeries were twice as common in the younger age group compared to the older one. There was no statistical difference in the time interval from diagnosis to surgery between the age groups $(p=0.89)$.

\section{Visual Acuity and Intraocular Pressure}

The mean presenting logMAR BCVA was $1.82 \pm 0.92$ for patients aged $\geq 85$ years and $1.21 \pm 0$ for the younger group $(p<0.0001)$. The mean IOP at presentation was $16.5 \pm 9.2$ $\mathrm{mmHg}$ and $15.9 \pm 6.2 \mathrm{mmHg}$, respectively $(p=0.52)$. 
Table 2 Distribution of Urgency of Pars-Plana Vitrectomy by Age Group

\begin{tabular}{|l|c|c|c|c|}
\hline Age Group (Years) & $\begin{array}{c}\text { Urgent } \\
\text { Number of Cases (\%) }\end{array}$ & $\begin{array}{c}\text { Mid Urgency } \\
\text { Number of Cases (\%) }\end{array}$ & $\begin{array}{c}\text { Low Urgency } \\
\text { Number of Cases (\%) }\end{array}$ & $\begin{array}{c}\text { Total } \\
\text { Number of Cases (\%) }\end{array}$ \\
\hline $75-84$ & $234(48.4)$ & $94(19.4)$ & $156(32.2)$ & $484(100)$ \\
85 and older & $70(65)$ & $21(19)$ & $17(16)$ & $108(100)$ \\
\hline
\end{tabular}

Note: Chi square $(3,2)=11.8856, p=0.002625$.

\section{Comparison of Patients Operated During 2008-20I3 to Those Operated During 2014-2018}

The mean and median age was similar throughout the study years (median of 80 years during 2008-2013 and 79.5 years during 2014-2018). There was no significant difference between the rates of any systemic disease, nor specifically for cardiovascular or neoplastic disease between the two time periods. The percentage of older patients who underwent elective surgeries in the first study period was $12 \%$ compared to $6 \%$ in the second study period. This difference did not reach a level of statistical significance.

The rate of surgery for SMH was significantly reduced in the later years of the study compared to the earlier years ( $11 \%$ versus $2 \%, p=0.000014$ ). There was no significant difference between the rates of surgeries for RD, ERM, diabetic complications, dropped IOL, or dropped lens (Table 3).

\section{Discussion}

This study was conducted in order to describe the epidemiology of the surgical indications of PPV among patients aged 75 years or older as defined by data retrieved from

Table 3 Comparison of Vitrectomy Indications During the First and Last Five Years of the Study

\begin{tabular}{|l|c|c|c|}
\hline & $\begin{array}{c}\text { 2008-2013 } \\
(\mathbf{n = 2 9 2 )}\end{array}$ & $\begin{array}{c}\text { 2014-2018 } \\
(\mathbf{n = 3 0 0 )}\end{array}$ & P value \\
\hline Retinal Detachment & 51 & 63 & NS \\
\hline SMH & 33 & 7 & 0.000014 \\
\hline ERM/VMT & 74 & 65 & NS \\
\hline $\begin{array}{l}\text { Diabetic VH \& } \\
\text { complications }\end{array}$ & 18 & 14 & NS \\
\hline Endophthalmitis & 8 & 16 & NS \\
\hline
\end{tabular}

Abbreviations: ERM, epiretinal membrane; VMT, vitreomacular traction; SMH, sub-macular hemorrhage; $\mathrm{VH}$, vitreous hemorrhage. the computerized medical records of a single ophthalmology institute over a 10-year period. Our findings suggest that indications for vitrectomy in the elderly vary with age. While surgeries for mid- and low-urgency level pathologies, such as ERM, VMT, and $\mathrm{MH}$, were more common in the younger age group, urgent surgeries, such as those for $\mathrm{SMH}$ and trauma, were significantly more common in the older age group. In addition, the rate of surgery for SMH decreased in the later years of the study.

The prevalence of posterior vitreous detachment reportedly increases with age. ${ }^{17}$ Vitreomacular traction and idiopathic macular holes represent a disruption of this normal, age-related process, whereas ERM is associated with a completed posterior vitreous detachment and was found in high prevalence in persons aged 75 years or more. ${ }^{18,19}$ The mean age for the occurrence of a macular hole was shown in several studies to be $64-70,{ }^{20}$ and that figure coincides with the age group with the highest incidence of posterior vitreous detachment. Our study results are in agreement with this general timeline, with there having been few macular hole $(5.5 \%)$ and VMT surgeries $(5.5 \%)$ in the $\geq 85$-year-old group.

Due to the increased prevalence of ERM with age, we expected a higher rate of surgeries in the older group of patients in our series, but we observed the opposite. Furthermore, that rate did not increase in the latter years of the study, despite advances in vitrectomy techniques. The reason for this interesting finding may be partially related to the fact that the surgical indications for ERM peeling are not standardized, and that the selection of surgical candidates is at the discretion of the surgeon. Surgeons may consider older age to be a limiting prognostic factor, consequently reducing the referral rates even though reports in the literature do not necessarily support that notion. ${ }^{21-24}$ Other factors that may explain the lower rates of elective vitrectomies in patients $\geq 85$ years of age may be related to referral patterns from community clinics, limitations of older patients in seeking ophthalmic medical care, and reluctance of patients and their families to consider elective surgery at an advanced age. 
In our series, urgent cases represented $65 \%$ of the surgeries performed in the older age group. Among the urgent cases, there was a significantly higher rate of surgeries for ocular trauma and SMH in the older age group compared to the younger age group. Severe ocular trauma necessitating hospitalization and treatment reportedly had a bimodal incidence, with a peak for persons aged 75 years and older. ${ }^{25}$ Specifically, the rate of perforating eye injuries was highest in this age group and associated with falls and previous ocular surgery. ${ }^{26}$ While there was no distinction between age groups above 75 years in previous reports, these findings are in agreement with our observations that older age was related to a higher rate of severe eye injury. The increased rate of surgery for ocular trauma in the older age group emphasizes the need for visual preservation in elderly patients in order to reduce the risk of falls.

SMH is a devastating complication of neovascular AMD. Among known risk factors for SMH are concurrent anticoagulation/aggregation treatment, hypertension, and combined treatment with photodynamic therapy and antiVEGF intravitreal injections. ${ }^{27}$ The Submacular Surgery Trial reported a median age of 77 years and a $35 \%$ rate of patients over 80 years of age with AMD-related SMH. ${ }^{28}$ This finding is consistent with our current results that SMH may be more prevalent in the older age group of patients with AMD. Interestingly, we found a significant decrease in the rates of surgery for SMH during 2014-2018 compared to 2008-2013. There are two possible explanations for this observation: one is that there was a shift in the surgeon's preference towards intravitreal injections following several reports of comparable outcomes using anti-VEGF intravitreal injections for $\mathrm{SMH} .{ }^{29-33}$ The second possibility may be that since more AMD patients received repetitive antiVEGF intravitreal injections, the incidence of SMH has decreased or, alternatively, its severity has been minimized to allow treatment with anti-VEGF intravitreal injection monotherapy to suffice. Further studies are required to better understand this shift.

The strength of our study is the large cohort of elderly patients whose data were collected over a period of 10 years. It does, however, have several limitations: This is a retrospective study based on clinical reports. As such, some information regarding medical and ocular history as well as complications not related to the retina may be under-reported. Also, we only reviewed cases of elderly patients who underwent surgery. In order to better understand the referral patterns of elderly patients to elective surgery, it may be necessary to also include those cases of patients who had retinal consultation but did not eventually undergo surgery.

In conclusion, our study results suggest that the oldest age group of patients are unique in their pathologies and indications for surgeries due to both ocular and systemic conditions. The risk of ocular surgery in the elderly population needs to be weighed carefully against the many benefits of vision preservation in that age group. With the advancement of surgical procedures, and shifting of mindset on the part of eye care professionals, more elderly patients with visual deterioration due to retinal pathology may be treated for vision preservation and improvement. Our striving as a society to maintain this rapidly growing sector of the population as an integral functioning part of the community should prompt our healthcare systems to make the necessary adjustments, the first step of which would be defining the elderly population's unique needs through epidemiological studies.

\section{Disclosure}

No author has any proprietary interest in the publication of this report. No grants or funds were received for this work.

\section{References}

1. Facts About ageing. World Health Organization- Ageing and life-course. Available from: https:/www.who.int/ageing/about/facts/ en/. Accessed September 30, 2014.

2. World report on vision. World Health Organization- publications. Available from: https:/www.who.int/publications/i/item/world-report -on-vision. Accessed October 8, 2019.

3. Harwood RH, Foss AJ, Osborn F, Gregson RM, Zaman A, Masud T. Falls and health status in elderly women following first eye cataract surgery: a randomised controlled trial. Br J Ophthalmol. 2005;89 (1):53-59. doi:10.1136/bjo.2004.049478

4. Rogers MA, Langa KM. Untreated poor vision: a contributing factor to late-life dementia. Am J Epidemiol. 2010;171(6):728-735. doi:10.1093/aje/kwp453

5. Lin MY, Gutierrez PR, Stone KL, et al. Vision impairment and combined vision and hearing impairment predict cognitive and functional decline in older women. $J$ Am Geriatr Soc. 2004;52 (12):1996-2002. doi:10.1111/j.1532-5415.2004.52554.x

6. Elyashiv SM, Shabtai EL, Belkin M. Correlation between visual acuity and cognitive functions. $\mathrm{Br} J$ Ophthalmol. 2014;98 (1):129-132. doi:10.1136/bjophthalmol-2013-304149

7. Mutoh T, Isome S, Matsumoto Y, Chikuda M. Cataract surgery in patients older than 90 years of age. Can J Ophthalmol. 2012;47 (2):140-144. doi:10.1016/j.jcjo.2012.01.009

8. Syam PP, Eleftheriadis H, Casswell AG, Brittain GP, McLeod BK, Liu CS. Clinical outcome following cataract surgery in very elderly patients. Eye (Lond). 2004;18(1):59-62. doi:10.1038/sj.eye.6700521

9. Lai FH, Lok JY, Chow PP, Young AL. Clinical outcomes of cataract surgery in very elderly adults. $J$ Am Geriatr Soc. 2014;62 (1):165-170. doi:10.1111/jgs.12590

10. Berler DK. Intraoperative complications during cataract surgery in the very old. Trans Am Ophthalmol Soc. 2000;98:127-132. 
11. Westcott MC, Tuft SJ, Minassian DC. Effect of age on visual outcome following cataract extraction. $\mathrm{Br} J$ Ophthalmol. 2000;84 (12):1380-1382. doi:10.1136/bjo.84.12.1380

12. Mönestam E, Wachmeister L. Impact of cataract surgery on the visual ability of the very old. Am J Ophthalmol. 2004;137(1):145-155. doi:10.1016/S0002-9394(03)00900-0

13. Parker JS, Ham L, Parker CP, Parker JS, Dockery PW, Melles GRJ. DMEK in super-seniors: clinical outcomes of descemet membrane endothelial keratoplasty performed in patients $\geq 90$ Years Old. Curr Eye Res. 2020;45(9):1031-1035. doi:10.1080/ 02713683.2020.1726407

14. Muto T, Ide T, Chikuda M, Machida S. Vitrectomy in patients over 90 years of age. Clin Ophthalmol. 2016;10:239-242. doi:10.2147/ OPTH.S95622

15. Anteby R, Barzelay A, Barak A. Vitrectomy in patients 85 years of age and older: surgical outcomes and visual prognosis. Clin Interv Aging. 2018;13:243-249. doi:10.2147/CIA.S154425

16. Moisseiev E, Davidovitch Z, Kinori M, Loewenstein A, Moisseiev J, Barak A. Vitrectomy for idiopathic epiretinal membrane in elderly patients: surgical outcomes and visual prognosis. Curr Eye Res. 2012;37(1):50-54. doi:10.3109/02713683.2011.614373

17. Hikichi T, Hirokawa H, Kado M, et al. Comparison of the prevalence of posterior vitreous detachment in whites and Japanese. Ophthalmic Surg. 1995;26(1):39-43.

18. Roth AM, Foos RY. Surface wrinkling retinopathy in eyes enucleated at autopsy. Trans Am Acad Ophthalmol Otolaryngol. 1971;75 (5):1047-1058.

19. Ben Ghezala I, Seydou A, Gabrielle PH, et al. Epidemiology of vitreomacular interface abnormalities using macular spectral-domain optical coherence tomography in an elderly population (The Montrachet study). Retina. 2021;41(1):60-67. doi:10.1097/ IAE.0000000000002802

20. Forsaa VA, Lindtøørn B, Kvaløy JT, Frøystein T, Krohn J. Epidemiology and morphology of full-thickness macular holes. Acta Ophthalmol. 2018;96(4):397-404. doi:10.1111/aos.13618

21. Asaria R, Garnham L, Gregor ZJ, Sloper JJ. A prospective study of binocular visual function before and after successful surgery to remove a unilateral epiretinal membrane. Ophthalmology. 2008;115 (11):1930-1937. doi:10.1016/j.ophtha.2008.05.020

22. Falkner-Radler CI, Glittenberg C, Hagen S, Benesch T, Binder S. Spectral-domain optical coherence tomography for monitoring epiretinal membrane surgery. Ophthalmology. 2010;117(4):798-805. doi:10.1016/j.ophtha.2009.08.034

23. Kim JH, Kim YM, Chung EJ, Lee SY, Koh HJ. Structural and functional predictors of visual outcome of epiretinal membrane surgery. Am J Ophthalmol. 2012;153(1):103-10.e1. doi:10.1016/j. ajo.2011.06.021
24. Shiono A, Kogo J, Klose G, et al. Photoreceptor outer segment length: a prognostic factor for idiopathic epiretinal membrane surgery. Ophthalmology. 2013;120(4):788-794. doi:10.1016/j. ophtha.2012.09.044

25. Tielsch JM, Parver L, Shankar B. Time trends in the incidence of hospitalized ocular trauma. Arch Ophthalmol. 1989;107(4):519-523. doi:10.1001/archopht.1989.01070010533025

26. Klopfer J, Tielsch JM, Vitale S, See LC, Canner JK. Ocular trauma in the United States. Eye injuries resulting in hospitalization, 1984 through 1987. Arch Ophthalmol. 1992;110(6):838-842. doi:10.1001/ archopht.1992.01080180110037

27. Stanescu-Segall D, Balta F, Jackson TL. Submacular hemorrhage in neovascular age-related macular degeneration: a synthesis of the literature. Surv Ophthalmol. 2016;61(1):18-32. doi:10.1016/j. survophthal.2015.04.004

28. Hawkins BS, Bressler NM, Miskala PH, et al. Surgery for subfoveal choroidal neovascularization in age-related macular degeneration: ophthalmic findings: SST report no. 11 Ophthalmology. 2004;111 (11):1967-1980

29. Stifter E, Michels S, Prager F, et al. Intravitreal bevacizumab therapy for neovascular age-related macular degeneration with large submacular hemorrhage. Am J Ophthalmol. 2007;144(6):886-892. doi:10.1016/j.ajo.2007.07.034

30. McKibbin M, Papastefanou V, Matthews B, Cook H, Downey L. Ranibizumab monotherapy for sub-foveal haemorrhage secondary to choroidal neovascularisation in age-related macular degeneration. Eye (Lond). 2010;24(6):994-998. doi:10.1038/eye.2009.271

31. Dimopoulos S, Leitritz MA, Ziemssen F, Voykov B, Bartz-Schmidt KU, Gelisken F. Submacular predominantly hemorrhagic choroidal neovascularization: resolution of bleedings under anti-VEGF therapy. Clin Ophthalmol. 2015;9:1537-1541. doi:10.2147/OPTH.S87919

32. Kim JH, Chang YS, Kim JW, Kim CG, Yoo SJ, Cho HJ. Intravitreal anti-vascular endothelial growth factor for submacular hemorrhage from choroidal neovascularization. Ophthalmology. 2014;121 (4):926-935. doi:10.1016/j.ophtha.2013.11.004

33. Shienbaum G, Garcia Filho CA, Flynn HW Jr, Nunes RP, Smiddy WE, Rosenfeld PJ. Management of submacular hemorrhage secondary to neovascular age-related macular degeneration with anti-vascular endothelial growth factor monotherapy. $\mathrm{Am}$ J Ophthalmol. 2013;155(6):1009-1013. doi:10.1016/j. ajo.2013.01.012
Clinical Interventions in Aging

\section{Publish your work in this journal}

Clinical Interventions in Aging is an international, peer-reviewed journal focusing on evidence-based reports on the value or lack thereof of treatments intended to prevent or delay the onset of maladaptive correlates of aging in human beings. This journal is indexed on PubMed Central, MedLine, CAS, Scopus and the Elsevier
Bibliographic databases. The manuscript management system is completely online and includes a very quick and fair peer-review system, which is all easy to use. Visit http://www.dovepress.com/ testimonials.php to read real quotes from published authors. 